\title{
PD-L1 expression and immune cells in anaplastic carcinoma and poorly differentiated carcinoma of the human thyroid gland: A retrospective study
}

\author{
SOLEDAD CAMESELLE-GARCÍA ${ }^{1}$, SÁMER ABDULKADER-SANDE ${ }^{2}$, MARÍA SÁNCHEZ-ARES ${ }^{2}$, \\ GEMMA RODRÍGUEZ-CARNERO ${ }^{3}$, JESÚS GARCIA-GÓMEZ ${ }^{1}$, FRANCISCO GUDE-SAMPEDRO ${ }^{4,5}$, \\ IHAB ABDULKADER-NALLIB ${ }^{2,5}$ and JOSÉ MANUEL CAMESELLE-TEIJEIRO ${ }^{2,5}$
}

\begin{abstract}
${ }^{1}$ Department of Medical Oncology, University Hospital Complex of Ourense, Galician Healthcare Service, 32005 Ourense; Departments of ${ }^{2}$ Pathology, ${ }^{3}$ Endocrinology and Nutrition, and ${ }^{4}$ Epidemiology, Clinical University Hospital of Santiago de Compostela, Health Research Institute of Santiago de Compostela, Galician Healthcare Service, 15706 Santiago de Compostela; ${ }^{5}$ School of Medicine, University of Santiago de Compostela, 15782 Santiago de Compostela, Spain
\end{abstract}

Received March 9, 2021; Accepted May 4, 2021

DOI: 10.3892/ol.2021.12814

\begin{abstract}
Anaplastic thyroid carcinoma (ATC) and poorly differentiated thyroid carcinoma (PDTC) have limited treatment options, and immune profiling may help select patients for immunotherapy. The prevalence and relevance of programmed death-1 ligand (PD-L1) expression and the presence of immune cells in ATC and PDTC has not yet been well established. The present study investigated PD-L1 expression (clone 22C3) and cells in the tumor microenvironment (TME), including tumor-infiltrating lymphocytes (TILs), tumor-associated macrophages (TAMs) and dendritic cells, in whole tissue sections of 15 cases of ATC and 13 cases of PDTC. Immunohistochemical PD-L1 expression using a tumor proportion score (TPS) with a $1 \%$ cut-off was detected in $9 / 15(60 \%)$ of ATC cases and $1 / 13(7.7 \%)$ of PDTC cases

Correspondence to: Dr José Manuel Cameselle-Teijeiro, Department of Pathology, Clinical University Hospital of Santiago de Compostela, Health Research Institute of Santiago de Compostela, Galician Healthcare Service, Travesía Choupana s/n, 15706 Santiago de Compostela, Spain

E-mail: josemanuel.cameselle@usc.es
\end{abstract}

Abbreviations: ATC, anaplastic thyroid carcinoma; DTC, differentiated thyroid carcinoma; FTC, follicular thyroid carcinoma; HCC, Hürthle (oncocytic) cell carcinoma; ICI, immune checkpoint inhibitor; MKIs, multi-tyrosine kinase inhibitors; MMR, mismatch repair; PD-L1, programmed death ligand 1; PDTC, poorly DTC; PTC, papillary thyroid carcinoma; TAMs, tumor-associated macrophages; TC, thyroid cancer; TILs, tumor infiltrating lymphocytes; TMB, tumor mutational burden; TME, tumor microenvironment; TPS, tumor proportion score; WHO, World Health Organization

Key words: ATC, PDTC, PD-L1, TME, microsatellite instability, immunotherapy
$(\mathrm{P}=0.006)$. PD-L1 expression in TILs was limited to the ATC group (73.3 vs. $0 \%$ in ATC and PDTC, respectively). In the ATC group, the TPS for tumor positive PD-L1 expression revealed a non-significant trend towards worse survival, but no difference was observed when investigating PD-L1 expression in TILs and TAMs. In addition to increased PD-L1 expression, all ATC cases exhibited significantly increased $\mathrm{CD}^{+}$and $\mathrm{CD}^{+} \mathrm{T}$ cells, $\mathrm{CD}^{+} 8^{+}$and $\mathrm{CD} 163^{+}$macrophages, and $\mathrm{S} 100^{+}$ dendritic cells compared with the PDTC cases. Loss of mutL homolog 1 and PMS1 homolog 2 expression was observed in one ATC case with the highest PD-L1 expression, as well as in the only PDTC case positive for PD-L1. Notably, the latter was the only PDTC case exhibiting positivity for p53 and a cellular microenvironment similar to ATC. The current results indicated that PD-L1 expression was frequent in ATC, but rare in PDTC. In addition to PD-L1, the present study suggested that microsatellite instability may serve a role in both the TME and the identification of immunotherapy candidates among patients with PDTC.

\section{Introduction}

Thyroid cancer (TC) is the most common endocrine malignant tumor, ranking ninth in incidence for both sexes and representing the fifth most prevalent cancer in women (1). Most TCs are derived from follicular cells and are classified into three main groups: a) differentiated thyroid carcinoma (DTC) which includes papillary thyroid carcinoma (PTC), follicular thyroid carcinoma (FTC) and Hürthle (oncocytic) cell carcinoma (HCC); b) poorly differentiated thyroid carcinoma (PDTC); and c) anaplastic thyroid carcinoma (ATC) (2).

PTC and FTC are the most common types of TC, have a low overall mortality and are generally curable by surgery with or without radioiodine treatment (3). ATCs are rare undifferentiated cancers with no effective therapy, having almost $100 \%$ disease-specific mortality (4-6). PDTCs show limited evidence of follicular cell differentiation and are 
morphologically and behaviorally intermediate between DTC and ATC $(2,7,8)$. PDTC generally shows a poor response to radioiodine treatment and has an overall 5-year survival rate of about $65 \%$, thus necessitating more effective therapies (2,8-10). Even slight amounts of PDTC areas $(\geq 10 \%)$ in a DTC affect the prognosis significantly (11). Some HCCs are also classified as PDTCs and have a worse prognosis than usual HCCs $(12,13)$.

Treatment of ATC must be carried out by a multidisciplinary team generally requiring the combination of surgery (as complete as possible), radiotherapy (intensity-modulated radiotherapy) and conventional chemotherapy using doxorubicin or taxanes (docetaxel or paclitaxel) usually with cisplatin or carboplatin (4-6). Because these treatments are generally not sufficient, newer therapies in development include single or multi-tyrosine kinase inhibitors (MKIs), vascular disruptors, and immunotherapy (6). Regarding MKIs, the Food and Drug Administration have approved the combined treatment with dabrafenib and trametinib for patients with locally advanced or metastatic ATC and somatic $B R A F^{\mathrm{V} 600 \mathrm{E}}$ mutation (14). Lenvatinib has demonstrated an acceptable safety profile for Japanese patients with unresectable thyroid tumors including ATC, regardless of mutational status (15). Other therapeutic options could include everolimus when somatic mutations have been detected in the PI3K/mTOR pathway $(16,17)$, imatinib when overexpression of PDGF receptors are detected in advanced ATC (18), and immune checkpoint inhibitor (ICI) drugs targeting PD-1 or PD-L1 $(6,19)$.

Programmed death ligand 1 (PD-L1), also designated as CD274 or B7-H1, is expressed on activated lymphocytes, dendritic cells, macrophages, healthy cells of different tissues and some tumor cells (20,21). Programmed cell-death 1 (PD-1, CD279) is a glycoprotein normally expressed by $\mathrm{T}$ lymphoid cells and macrophages. The binding of PD-1 to its ligands PD-L1 and PD-L2 inhibits cytotoxic $\mathrm{CD}^{+} \mathrm{T}$ cell immune response and facilitates the escape of the immune response to cells expressing these ligands $(20,21)$. Blockade of PD-L1 was effective in inhibiting ATC in an in vivo model (BALB/c nude mice with human ATC cells) (22). Using an immunocompetent mouse model of orthotopic ATC, the combination of a $B R A F^{\mathrm{V} 600 \mathrm{E}}$ inhibitor and anti-PD1/PD-L1 antibody dramatically improved mouse survival with a tumor reduction along with an increase in cytotoxic $\mathrm{CD}^{+} \mathrm{T}$ cells, NK cells and M1-polarized tumor-associated macrophages (23). Additional studies in a mouse model of orthotopic ATC confirmed that increased efficacy in reducing tumor size and improving survival using an anti-PD1/PD-L1 checkpoint inhibitor combined with an MKI (lenvatinib) was associated with a modification of ATC microenvironment (24). Indoleamine 2,3-dioxygenase (IDO1) has been associated with an altered tumor immune response; therefore IDO1 inhibitors are being investigated in clinical trials in combination with other ICIs (25).

A phase Ib proof-of-concept study of the anti-PD-1 antibody pembrolizumab in patients with advanced, PD-L1-positive PTC or FTC evidenced antitumor activity in a minority of patients treated (26). Another phase 2 trial of pembrolizumab combined with chemoradiotherapy showed good initial tolerance and effectiveness in locoregional disease control but resulted in disappointing survival outcomes (27). A retrospective study of twelve ATC patients, however, showed that in a subset of patients with ATC, pembrolizumab may be an effective salvage therapy added to kinase inhibitors (lenvatinib, dabrafenib + trametinib, trametinib alone) at the time of progression of these drugs, encouraging the incorporation of immunotherapy in patients with ATC (28). Another recent phase II clinical trial to evaluate the efficacy and tolerability of a humanized monoclonal antibody that binds PD-1 and blocks its interaction with PD-L1 (spartalizumab) was carried out in forty-two ATC patients (19). Interestingly, this study evidenced a tumor response of $52.1 \%$ in the PD-L1-positive population and that response was independent of $B R A F$ mutational status (19). Several prospective studies are being conducted using ICIs for the treatment of patients with ATC (6), and an improvement in the understanding of the immune microenvironment and the immune biomarkers associated with these highly aggressive thyroid tumors is highly relevant.

Thus, the aim of this study was to evaluate the expression of PD-L1 and the tumor microenvironment in a series of ATCs and PDTCs. We investigated the immunohistochemical expression of PD-L1 in tumor cells, tumor-infiltrating lymphocytes (TILs) and tumor associated macrophages (TAMs), along with the phenotypes of TILs, TAMs and other cells.

\section{Materials and methods}

Clinicopathological features. We retrospectively analyzed the clinicopathological data of a series of 26 patients who had undergone total or partial thyroidectomy for ATC and/or PDTC at the Clinical University Hospital of Santiago de Compostela (CHUS) and at the University Hospital Complex of Ourense (CHOU), Spain. The inclusion criteria included having a sufficient excess of tumor tissue fixed in neutral, phosphate-buffered, $10 \%$ formalin and included in paraffin blocks for additional immunohistochemical studies. Fifteen patients had ATC and 11 patients had PDTC; PDTC areas coexisted with ATC in two patients and these were also included in the study. The patients consisted of $8(30.7 \%)$ men and $18(69.2 \%)$ women. The age of patients ranged from 47 to 77 years with a mean age of $64.53 \pm 11.29$ years (range $47-83$ ) for ATC patients and 73.5 \pm 6.63 years (range 55-87) for PDTC patients $(\mathrm{P}=0.018)$. The patients were followed from the time of histopathological diagnosis until death or the moment of the last clinical follow-up, and clinical data were retrieved from electronic medical records. The original hematoxylin-eosin (H\&E) slides from all cases were reviewed by two expert thyroid pathologists (IA-N and JMC-T) and of each case, a paraffin block containing sufficient representative tumor tissue was selected for the additional immunohistochemical analyses of the present study. Tumors were classified according to the criteria of the latest World Health Organization (WHO) thyroid tumor classification (2). All tissue samples were provided by the Biobank of CHUS, integrated in the Spanish National Biobank Network. The study was performed in accordance with the declaration of Helsinki (and subsequent ratifications) and approved by the Santiago-Lugo Medical Research Ethics Committee (code: 2019/275). Written informed consent was obtained.

Immunohistochemical study. Paraffin-embedded tumor tissue sections were stained with H\&E, and the immunohistochemical analyses were also performed on 
$4 \mu \mathrm{m}$-thick paraffin tissue sections with a peroxidase-conjugated labeled dextran polymer (EnVision FLEX/HRP; Dako), using 3,3'-diaminobenzidine as the chromogen (GC80611-2; Dako). The primary antibodies and the conditions of use (clone, concentration, antigenic recovery treatment and manufacturer) were as follows: Thyroglobulin (TG) (code GA509, polyclonal, ready-to-use, pH 6; Dako); calcitonin (code GA515, polyclonal, ready-to-use, pH 6; Dako); PD-L1 (code GE006, clone 22C3, PD-L1 IHC 22C3 pharmDx, ready-to-use, pH 6; Dako), CD3 (code IR503, polyclonal, ready-to-use, pH 9; Dako); CD4 (code IR649, clone 4B12, ready-to-use, pH 9; Dako); CD8 (code IR623, clone C8/144B, ready-to-use, pH 9; Dako); CD20 (code IR604, clone L26, ready-to-use, pH 9; Dako); CD68 (code IR613, clone PGM1, ready-to-use, pH 9; Dako); CD163 (code CM353AK, clone 10D6, dilution 1:100, pH 9; Biocare Medical); S100 protein (code IR504, polyclonal, ready-to-use, pH 9; Dako); p53 (code IR616, clone DO-7, ready-to-use, pH 9; Dako); MLH1 (code IR079, clone E605, ready-to-use, pH 9; Dako); MLH2 (code IR085, clone FE11, ready-to-use, pH 9; Dako); MSH6 (code IR086, clone EP49, ready-to-use, pH 9; Dako); and PMS2 (IR087, clone EP51, ready-to-use, pH 9s; Dako). Non-tumorous thyroid tissue adjacent to carcinoma (for thyroglobulin, MLH1, MSH2, MSH6 and PMS2), a medullary thyroid carcinoma (for calcitonin), a lung adenocarcinoma (for PD-L1), a colon cancer (for p53), and normal lymphoid tissue of palatal tonsil (for CD3, CD4, CD8, CD20, CD68, CD163, and S100) have been used as positive controls. Non-immune rabbit and mouse serum samples were substituted for the primary antibodies as negative control samples.

All immunostains were evaluated simultaneously by 2 investigators (IA-N and JMC-T) using a double-head optical microscope (BX41TF; Olympus) until consensus was reached. Only PD-L1 membranous staining of viable tumor cells was evaluated and the tumor proportion score (TPS) represented the percentage of PD-L1-positive tumor cells relative to all viable tumor cells. A cutoff score $\geq 1 \%$ was used to define PD-L1 positivity. PD-L1 membranous staining was also scored in TILs and TAMs; stromal immune cells distant from the tumor were excluded. Membranous staining for CD4, CD8, and CD163, membranous/cytoplasmic staining for CD3, CD20, CD68, and cytoplasmic/nuclear staining for S100 were scored as 0 (negative), 1 (positive $\leq 10 \%$ of inflammatory cells), 2 (between 11 and $49 \%)$ and $3(\geq 50 \%)$. Only nuclear staining was considered positive for MLH1, MSH2, MSH6 and PMS2. For p53, diffuse and strong nuclear staining (so-called 'block staining') and complete loss of staining ('null' phenotype) were considered positive (associated with mutations), while scattered, often weak nuclear positivity was considered a negative ('wild-type') normal p53 staining pattern.

Statistical analysis. The chi-square and Fisher's exact tests were, where appropriate, used to investigate the association between categorical variables. Student's t-test was used to evaluate the statistical significance of the difference in the means between the two groups. Survival analysis of differences between groups (ATC vs. PDTC and PD-L1+ vs. PD-L1-) was performed using the Kaplan-Meier method with the log-rank test. Differences with $\mathrm{P}<0.05$ were considered statistically significant. All statistical analyses were performed using $\mathrm{R}$ statistical software (version 4.0.3).

\section{Results}

The main clinicopathological and immunohistochemical characteristics of the study are shown in Tables I and II. In the ATC group $(n=15), 60 \%$ of the patients were women and $40 \%$ were men. Of the 15 ATC cases, $9(60 \%)$ tumors were morphologically subclassified as giant cell pattern, $3(20 \%)$ as spindled cell pattern, and $3(20 \%)$ as epithelial (squamoid) cell pattern (Table I). In the PDTC group $(n=11), 81.8 \%$ of the patients were women and $18.2 \%$ were men. Survival data appear in Table I and Fig. 1. Significant differences in survival were found when comparing ATC and PDTC $(\mathrm{P}=0.0001)$; while $86.6 \%$ of patients with ATC had died from the tumor after a mean follow-up of 5 months (range $0.1-16$ ), only $54.5 \%$ of the patients with PDTC (without anaplastic component) had died after a mean follow-up of 84.22 months (range 3.3-237) (Fig. 1)

The epithelial non-tumorous thyroid tissue adjacent to PDTCs and ATCs showed positivity for thyroglobulin, MLH1, MSH2, MSH6 and PMS2, but negativity for calcitonin, p53, PD-L1, CD3, CD4, CD8, CD20, CD68 and S100 (Figs. S1-S4). All ATC tumors were negative for thyroglobulin (Fig. 2B) and calcitonin while all PDTC tumors were positive for thyroglobulin but negative for calcitonin. In the immunohistochemical evaluation of PDTC areas present in the thyroid tumors of two patients who had ATC, both tumor types were evaluated independently as PDTCs and ATCs. Heterogeneous (focal or multifocal) positivity for PD-L1 in tumor cells was detected in $60 \%$ of ATC cases, in which the percentage of positive tumor cells ranged from 15 to $90 \%$ (Tables I and II). Positivity for PD-L1 was detected in all cases of ATC with epithelial cell pattern and also in different cases with other ATC patterns (Figs. 2-4). PD-Llexpression in ATC tumor cells was significantly higher than that in PDTC cases (60\% vs. 7.7\%, $\mathrm{P}=0.006$ ) (Table II). The only case of PDTC with PD-L1 positive tumor cells (35\%) was the one case of oncocytic cells, a poorly differentiated Hürthle cell carcinoma (case 19) (Fig. 3). In the ATC group, a slightly higher number of cases showed positivity for PD-L1 in TILs than in tumor cells $(73.3 \%$ vs. 60\%), but neither PD-L1-positive TILs nor TAMs were observed in the PDTC group $(\mathrm{P}=0.000)$ (Figs. 2-4). Using TPS, PD-L1-positive ATC patients showed a trend for worse survival than those with PD-L1-negative tumors (Fig. 1B), although the differences were not significant $(\mathrm{P}=0.15)$. No difference in relation to survival was found when comparing the expression of PD-L1 in ATC-TILs or TAMs ( $\mathrm{P}=0.81)$ (Fig. 1C).

Significant differences were found in the expression of lymphocytic markers in ATC and PDTC (Tables I and II). All ATC cases showed CD3 and CD8 positive cells as well as a higher percentage of CD4 and CD20 positive cells, while no positivity for CD4 and CD20 was detected in PDTC cases; when comparing the expression of all these lymphoid markers in ATC and PDTC, the differences were significant (Table II). All ATCs showed a higher and significant percentage of CD68, CD163 and S100 positive cells compared to the group of PDTCs (Table II) (Figs. 2,3 and 5). While 11/15 (73.3\%) of the ATCs showed an abnormal pattern of p53 protein expression, all PDTC cases except the poorly differentiated Hürthle cell carcinoma case $(7.7 \%)$ showed a p53 wild-type (i.e., normal) 

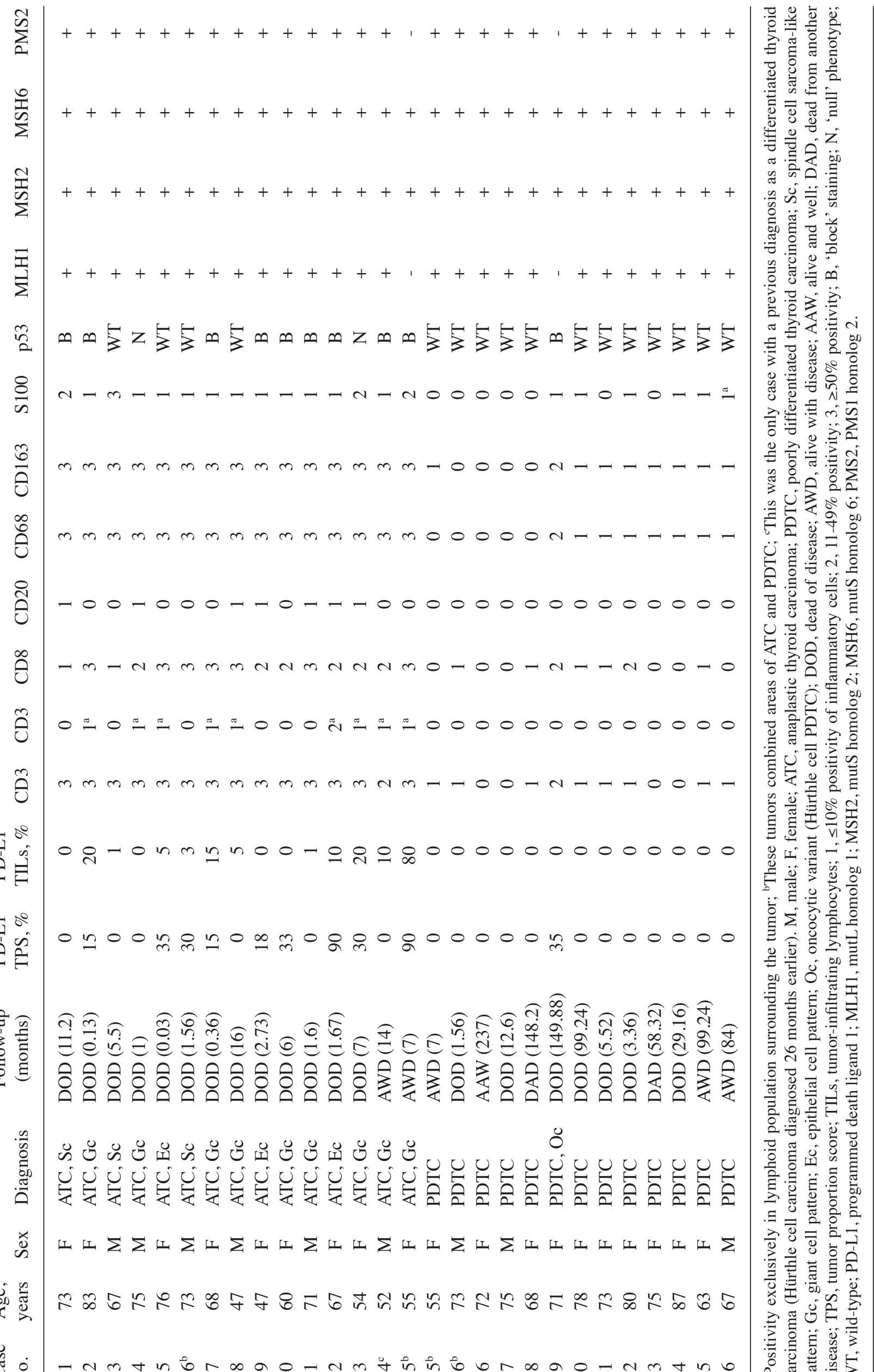

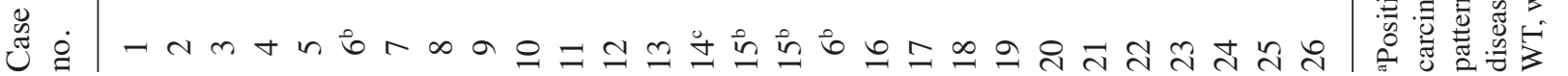


Table II. Comparison of clinicopathological and immunohistochemical data between 15 cases of ATC and 13 cases of PDTC in 26 patients $^{\mathrm{a}}$.

\begin{tabular}{|c|c|c|c|}
\hline Characteristics & ATC & PDTC & P-value \\
\hline Age, years & & & 0.018 \\
\hline Median & 67 & 73 & \\
\hline Mean \pm SD $($ range $)$ & $64.53 \pm 11.29(47-83)$ & $73.55 \pm 6.63(55-87)$ & \\
\hline Sex, n/total (\%) & & & 0.395 \\
\hline Male & $6 / 15(40.0)$ & 2/11 (18.2) & \\
\hline Female & $9 / 15(60.0)$ & 9/11 (81.8) & \\
\hline \multicolumn{4}{|l|}{ PD-L1 } \\
\hline TPS & $9 / 15(60.0)$ & $1 / 13(7.7)$ & 0.006 \\
\hline TILs & $11 / 15(73.3)$ & $0 / 13(0.0)$ & $<0.001$ \\
\hline CD3 & $15 / 15(100.0)$ & 9/13 (69.2) & 0.035 \\
\hline CD4 & $9 / 15(60.0)$ & $0 / 13(0.0)$ & 0.001 \\
\hline CD8 & $15 / 15(100.0)$ & $7 / 13(53.8)$ & 0.005 \\
\hline CD20 & $7 / 15$ (46.7) & $0 / 13(0.0)$ & 0.007 \\
\hline CD68 & $15 / 15(100.0)$ & $8 / 13(61.5)$ & 0.013 \\
\hline CD163 & $15 / 15(100.0)$ & 9/13 (69.2) & 0.035 \\
\hline S100 & $15 / 15(100.0)$ & $6 / 13(46.2)$ & 0.001 \\
\hline p53 & $11 / 15(73.3)$ & $1 / 13(7.7)$ & 0.001 \\
\hline
\end{tabular}

${ }^{a}$ Among the 26 patients, coexistence of ATC and PDTC areas was observed in the tumors of 2 patients. ATC, anaplastic thyroid carcinoma; PDTC, poorly differentiated thyroid carcinoma; TPS, tumor proportion score; TILs, tumor-infiltrating lymphocytes; PD-L1, programmed death ligand 1.

staining pattern $(\mathrm{P}=0.001)$. Expression of DNA mismatch repair (MMR) proteins was detected in all cases except in one single case with negativity for MLH1 and PMS2 in the ATC areas and concomitant positivity for MLH1 in PDTC areas, as well as in another case of PDTC (case 19) with a complete loss of nuclear MLH1 and PMS2 expression (Fig. 3).

\section{Discussion}

The immunohistochemical expression of PD-L1 is sometimes a prerequisite for the establishment of checkpoint inhibitor therapy and has prognostic value in several types of malignant tumors $(21,29)$. Based on the encouraging results of trials involving immunotherapy in the management of ATC (25), we have investigated PD-L1 expression and tumor microenvironment (TME) in a series of 15 ATCs and 13 PDTCs.

Thyroid carcinogenesis arises and progresses gradually as a result of the accumulation of various genetic and epigenetic alterations $(2,30,31)$. There are early driver mutations shared by more than one category of thyroid tumors $(31,32)$ and DTCs have a relatively low level of somatic mutations compared to cancers from other sites $(33,34)$. The rate of mutations, however, is higher in the PDTC group than in the DTC group $(35,36)$ and is much higher in the ATCs $(37,38)$. This model of tumor progression is also supported, as in cases 6 and 15 of our series, by the coexistence of differentiated and less-differentiated areas in some thyroid tumors $(39,40)$. The existence of cases of patients with DTC whose tumor recurrence and/or metastasis included a PDTC and/or an
ATC (41) also supports this model; the possibility of two independent tumors, however, cannot be excluded. The mean age of patients with TC increases in relation with the loss of tumor differentiation (2), further supporting the sequential model of carcinogenesis. The older mean and median age of the 13 patients with PDTC in our series contrasted with the findings of other studies $(42,43)$, but this could be attributed to biases due to pathological diagnostic criteria and/or the limited number of cases. The tumors in our series were classified according to the WHO (2), applying the Turin criteria (and algorithm) (7), which by definition exclude PTCs. Other groups, such as the Memorial Sloan Kettering Cancer Center (MSKCC) group, consider PDTC to be any carcinoma with follicular cell differentiation that shows fresh tumor necrosis and/or presence of $\geq 5$ mitoses/10 high power microscopic fields (x400), thus also including PTC-derived cases $(42,44)$. Given that PTC is more common in young adults, the exclusion of PTCs with a $B R A F$-like signature from the group of PDTCs in our series could explain the differences $(31,32)$. These different diagnostic criteria (PDTC-Turin vs. PDTC-MSKCC), do, in fact, explain the variations in the prevalence of 'early' genomic alterations in PDTC (RAS mutations vs. $B R A F^{\mathrm{V} 600 \mathrm{E}}$ mutations, respectively) $(36,45)$.

In our series we found immunohistochemical positivity for PD-L1 in tumor cells (TPS) of more than half of the ATCs $(60 \%)$ but in only one case of PDTC (7.7\%). Similarly, PD-L1 expression was detected in TILs and TAMs from the ATC group (73.3\%) but not in the PDTC group, probably related to the higher mutational load of ATCs $(37,38)$. A few studies reported the expression of PD-L1 in TCs. PD-L1 


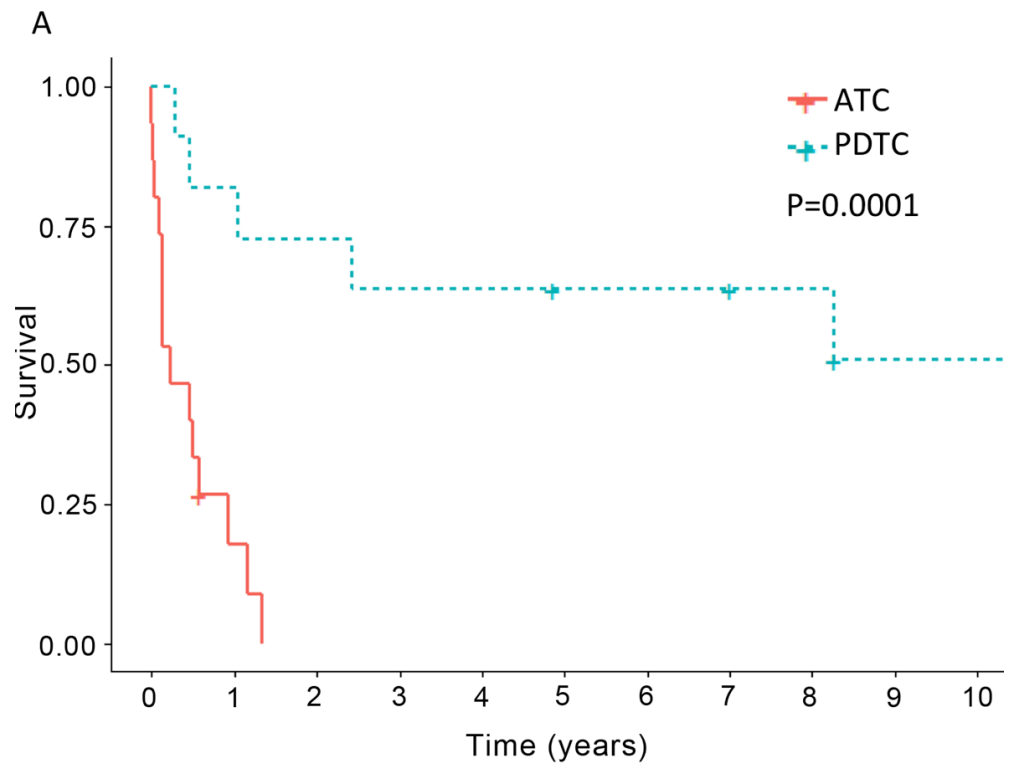

\section{B}
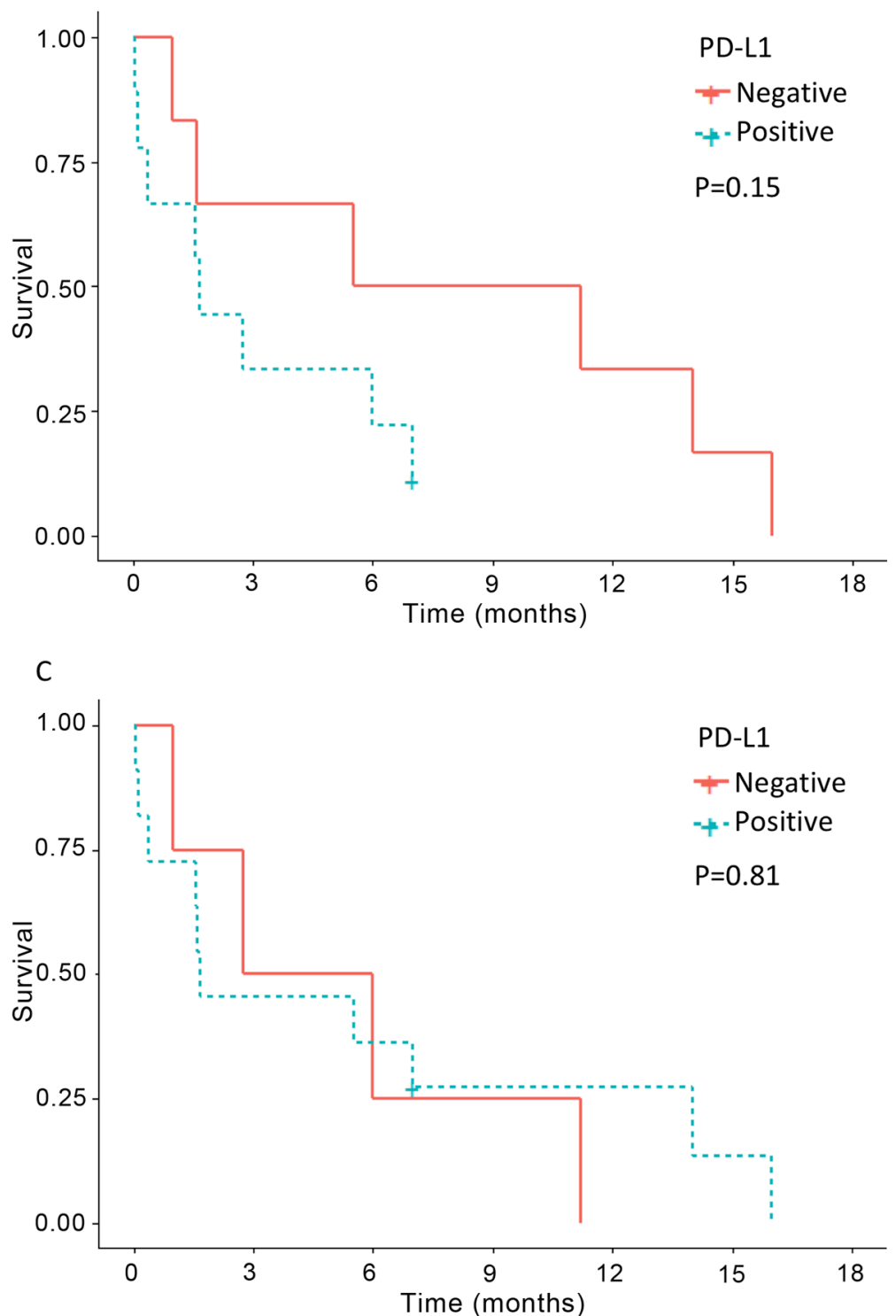

Figure 1. Survival and PD-L1 expression in patients with ATC and PDTC. (A) Kaplan-Meier analysis showing significant differences in survival between patients with ATC and PDTC. (B) Patients with PD-L1-positive ATC showed a trend for worse survival than those with PD-L1-negative tumors, although the difference was not significant. (C) No difference in survival was observed when comparing positive PD-L1 expression with negative PD-L1 expression in ATC lymphocytes and macrophages. ATC, anaplastic thyroid carcinoma; PDTC, poorly differentiated thyroid carcinoma; PD-L1, programmed death ligand 1. 
A

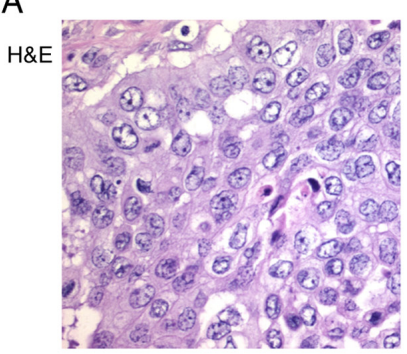

D

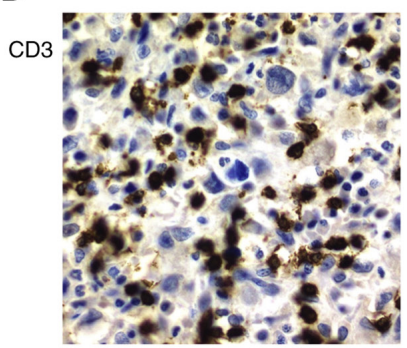

G

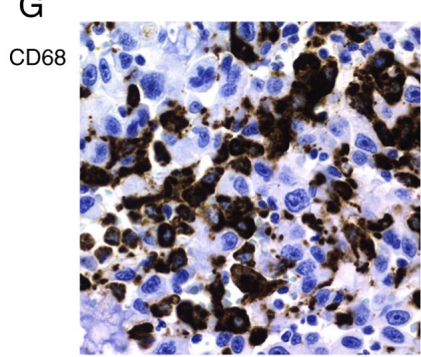

J

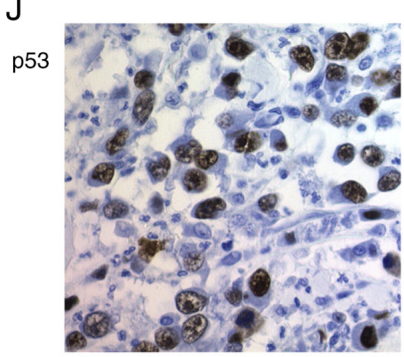

B

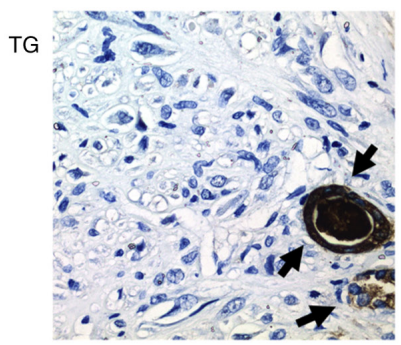

E

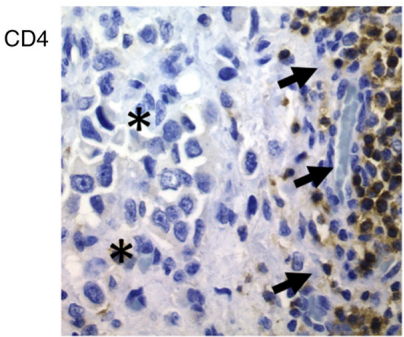

$\mathrm{H}$

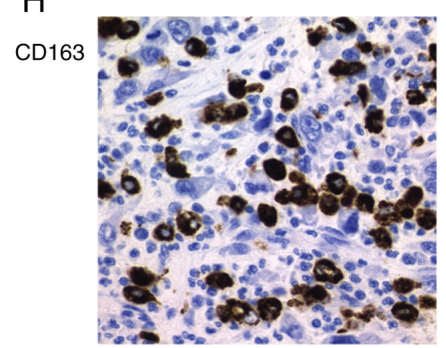

\section{K}

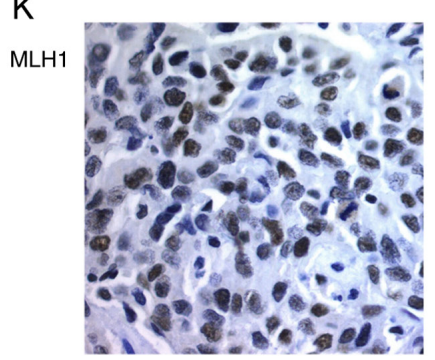

C

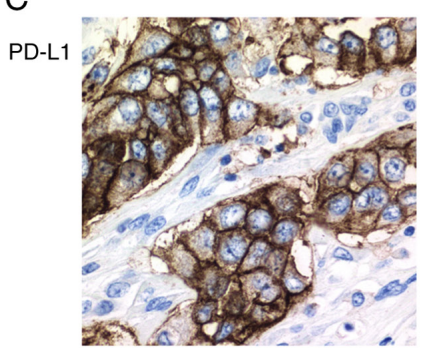

F

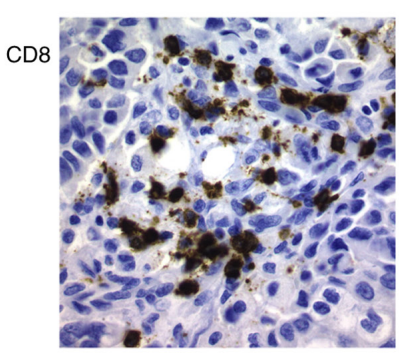

I
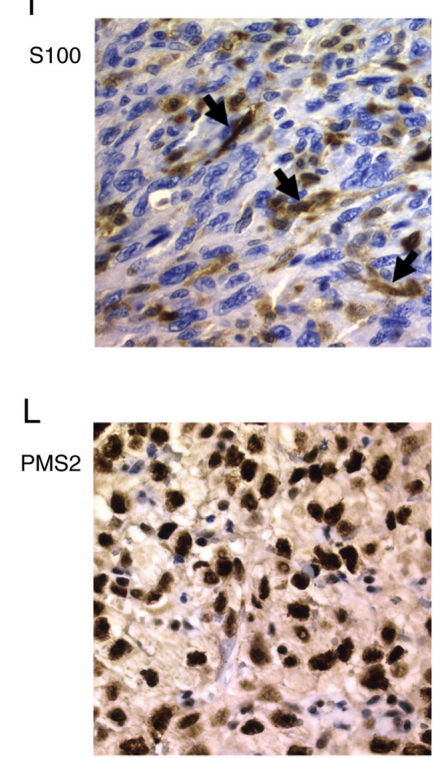

Figure 2. Immunohistochemical staining of ATC tissues. (A) H\&E staining of ATC with epithelial pattern. (B) All ATC cases were negative for TG; positively stained follicles (arrows) were normal cells entrapped by the tumor cells (internal control). (C) Strong positivity for PD-L1 was detected in some ATC cases. (D) $\mathrm{CD}^{+}$lymphocytes were found in all ATC cases. (E) $\mathrm{CD}^{+}$lymphocytes (arrows) were found exclusively surrounding the tumor (asterisks). (F) $\mathrm{CD} 8^{+}$ lymphocytes, (G) $\mathrm{CD}^{+} 8^{+}$and (H) $\mathrm{CD} 63^{+}$macrophages, and (I) S100 dendritic cells were found in all ATC cases. Positivity for (J) p53, (K) MLH1 and (L) PMS2 was a common finding in ATC. Magnification, x400. ATC, anaplastic thyroid carcinoma; H\&E, hematoxylin and eosin; TG, thyroglobulin; PD-L1, programmed death ligand 1; MLH1, mutL homolog 1; PMS2, PMS1 homolog 2.

immunoexpression was found in 6.1 to $82.5 \%$ of PTCs $(46,47)$, including cases of papillary thyroid microcarcinoma (48) and cases with simultaneous chronic thyroiditis and $B R A F$ mutation $(29,49)$. In PTCs a significant association between PD-L1 expression and $B R A F^{\mathrm{V} 600 \mathrm{E}}$ mutation has been reported in several studies $(48,49)$. Positivity for PD-L1 (clone E1L3N) and IDO1 was detected in $7 / 28(25 \%)$ and $2 / 28(7.1 \%)$ respectively of a series of PDTCs (50). Positivity for PD-L1 using different antibodies (clones SP142, 5H1, E1L3N, SP142, E1L3N, 22C3, 22C3, SP263 and SP263 respectively) was detected in 2/9 (22.2\%) (47), $3 / 13$ (23.1\%) (51), 14/49 (28.6\%) (52), 6/8 (75\%) (53), 13/16 (81.2\%) (54), 1/1 (100\%) (55), 1/1 (100\%) (56), 1/1 (100\%) (22), $1 / 1(100 \%)(57), 10 / 10(100 \%)(28)$ of the ATCs but in none of the $6(0 \%)$ PDTCs studied by Ahn et al (47). Mutation load or tumor mutational burden (TMB) represents the amount of somatic coding, base substitution and indel mutations per megabase of genome studied in each tumor, and high TMB is considered a new biomarker of sensitivity to ICIs (34). It has been postulated that a greater number of mutations would imply more neoantigens and consequently more targets for activated immune cells, which is why these tumors are good candidates for immune checkpoint inhibitor therapy (21,58-60). In human carcinogenesis, high TMB is mainly related to germline or somatic alterations in the DNA MMR complex (61-63), related to defects in genes involved in the recognition and removal of errors during lagging- and leading-strand DNA replication such as POLDI and POLE 
A

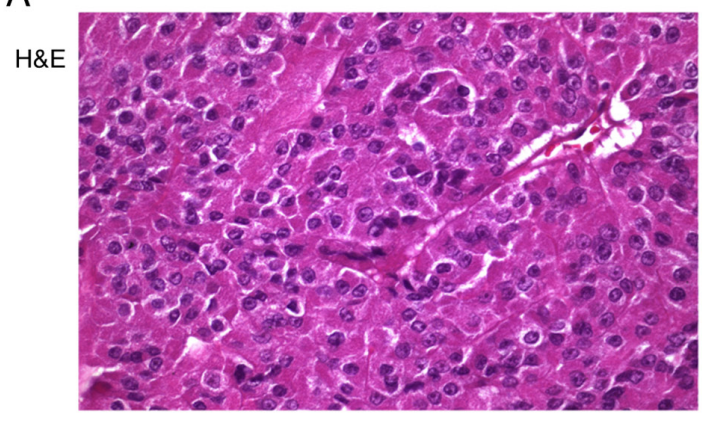

C

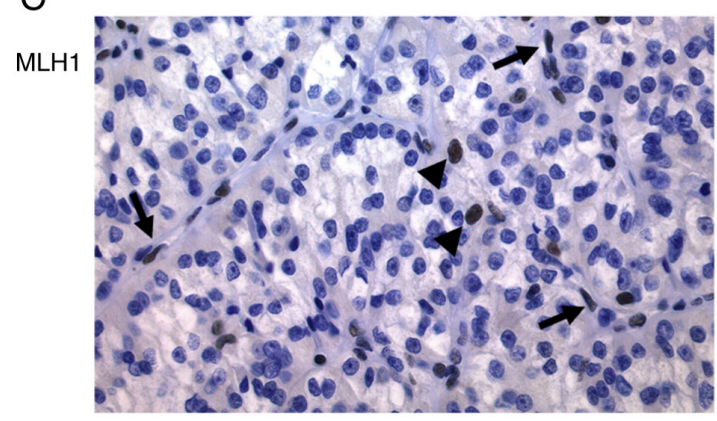

B

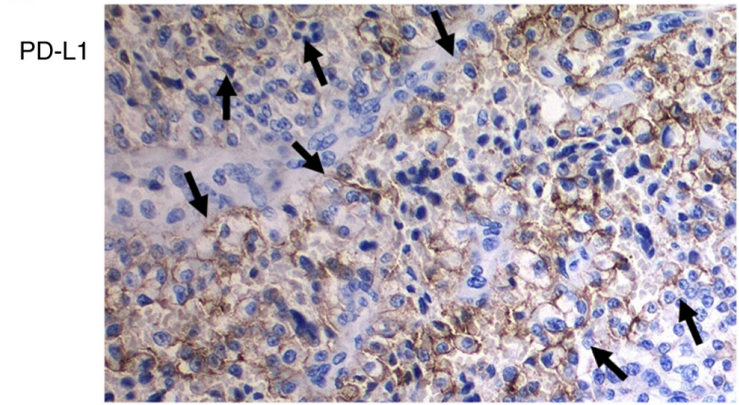

D

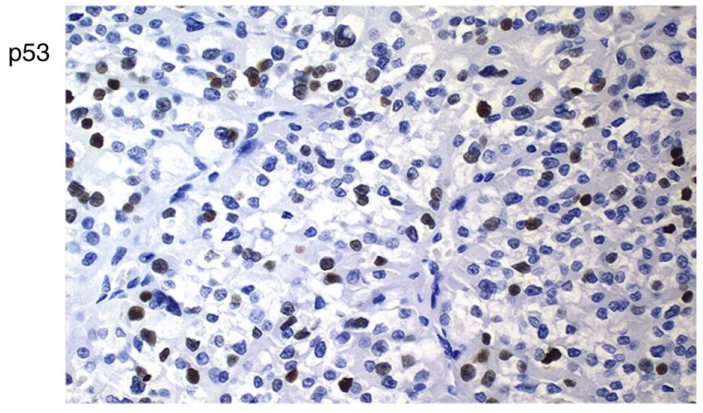

Figure 3. Poorly differentiated thyroid carcinoma (Hürthle cell variant; case 19). (A) H\&E staining. (B) Strong positivity for PD-L1 (arrows). (C) Tumor cells were negative for MLH1, but positivity was observed in stromal cells, endothelial cells (arrows) and lymphocytes (arrowheads) (internal control). (D) Strong positivity for p53. Magnification, x400. H\&E, hematoxylin and eosin; PD-L1, programmed death ligand 1; MLH1, mutL homolog 1.

genes, respectively (64-66), and/or related to loss of function mutations in the TP53 gene $(67)$, and other alterations $(68,69)$. ATCs are tumors with a high mutational load (37), usually accompanied by mutations of the TP53 gene $(31,37)$, which in our series was detected in $73.3 \%$ of ATCs. In the tumor of one of the patients in our series (case 15) (Fig. 5), the ATC areas showed the highest positivity for PD-L1, positivity for p53 and loss of expression of MLH1 and PMS2, while the areas of PDTC showed negativity for PD-L1, a wild type pattern for $\mathrm{p} 53$ and conservation of the protein expression of the MMR genes. On the other hand, in the other tumor combining anaplastic and poorly differentiated areas (case 6) (Fig. 4), the expression of PD-L1 was limited to the ATC areas without detecting alterations related to p53 or the MMR genes in any of the different tumor areas. Interestingly, the only PDTC case with PD-L1 expression (case 19) (Fig. 3), also showed positivity for p53, but loss of MLH1 and PMS2 expression, fitting with the proposed hypermutator role of the MLH mismatch-repair genes reported in ATCs (37). In colorectal cancer, a significantly higher expression of PD-L1 was detected in tumors exhibiting MMR deficiency and $B R A F$ mutation (40); this also agrees with the data from our series since $B R A F$ mutation is commonly an early event in the progression from conventional (BRAF-like) PTC to ATC. $B R A F^{\mathrm{V} 600 \mathrm{E}}$ mutation does not participate, however, in the development of the PDTC defined by the Turin criteria (31).

Our study evidenced significant differences in TME between the ATC and PDTC groups (Table II). Similar to our data, a recent study using fluorescence multiplex immunohistochemistry found significant differences between ATC and advanced DTC in relation to PD-L1 expression and lymphoid infiltration (70). We found an exclusive presence of $\mathrm{CD}^{+} \mathrm{CD}^{+}$(cytotoxic) $\mathrm{T}$ lymphoid population and $\mathrm{S}_{100}{ }^{+}$dendritic cells infiltrating the tumor cells, with a minority of helper $\left(\mathrm{CD}^{+}\right) \mathrm{T}$ lymphocytes at the interface of the tumor/normal thyroid tissue in all ATCs but in only one case (case 19) of PDTC. The role of TILs in PTC is controversial since its association with both a favorable (71) and an unfavorable $(72,73)$ prognosis has been described. More specifically, a protumorigenic role of FoxP3 ${ }^{+}$regulatory $\mathrm{T}$ cells (Treg) in DTC has been demonstrated while $\mathrm{CD}^{+} \mathrm{T}$ cells develop an antitumor function (73,74). In fact, exhausted PD- $1^{+} \mathrm{CD}^{+} \mathrm{T}$ lymphocytes appeared to be a marker of bad prognosis and immunosuppression in DTC $(73,74)$. In PTCs, $\mathrm{S}_{100}{ }^{+}$dendritic cells were more numerous when compared to normal thyroid tissue (75), and $\mathrm{CD}^{+} \mathrm{a}^{+}$dendritic cell density was associated with better disease-free survival (71). Significant differences between ATCs and PDTCs were also observed in our series in relation to tumor infiltration by TAMs using a histiocytic pan-marker (CD68) as well as CD163, a member of a scavenger receptor cysteine-rich superfamily restricted to the monocyte/macrophage lineage (histiocytic differentiation). Our data confirmed previous observations indicating the over-representation of pro-tumor TAMs in ATC and in advanced DTCs (71). Our images also strongly support the existence of a very dense network of interconnected CD163 ${ }^{+}$ macrophages in direct contact with intermingled cancer cells that may trap cells in the tumor stroma (76), where they correlate with poorer survival (71). Compared with type 1 inflammatory macrophages, type 2 suppressor macrophages $\left(\mathrm{CD}_{163^{+}}\right)$promote invasiveness of human TC cell lines (77) and have also been associated with a worse prognosis in cancers of other locations $(78,79)$. Our findings are consistent with a relationship between high TMB of ATC, expression 
A

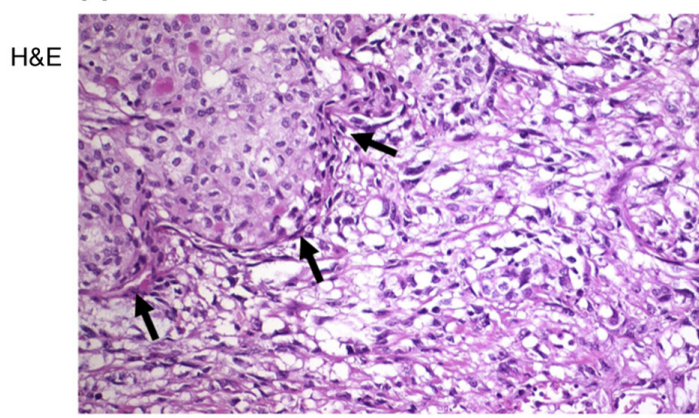

D

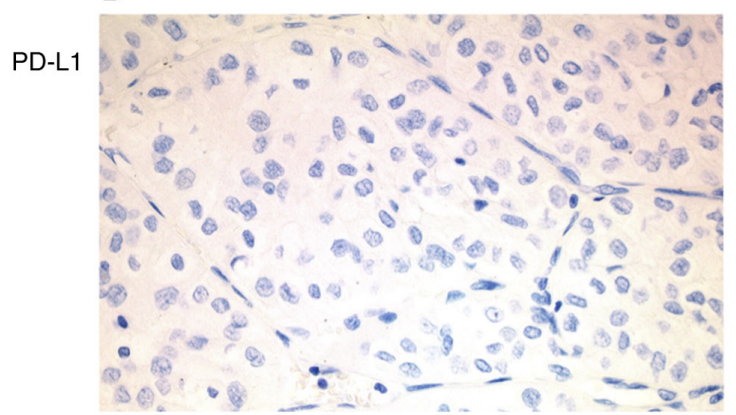

F

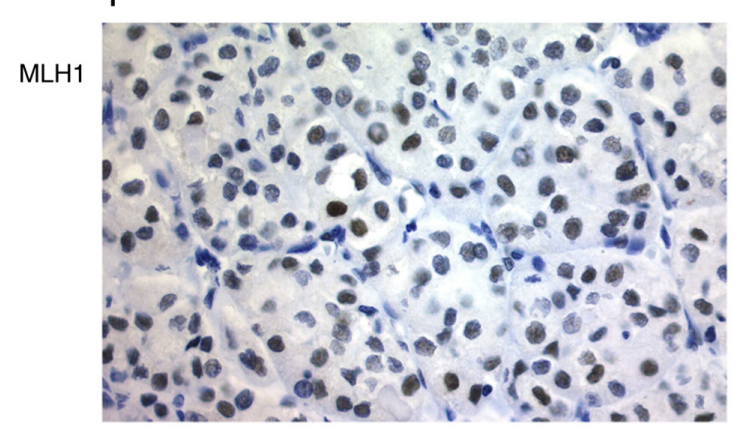

$\mathrm{H}$

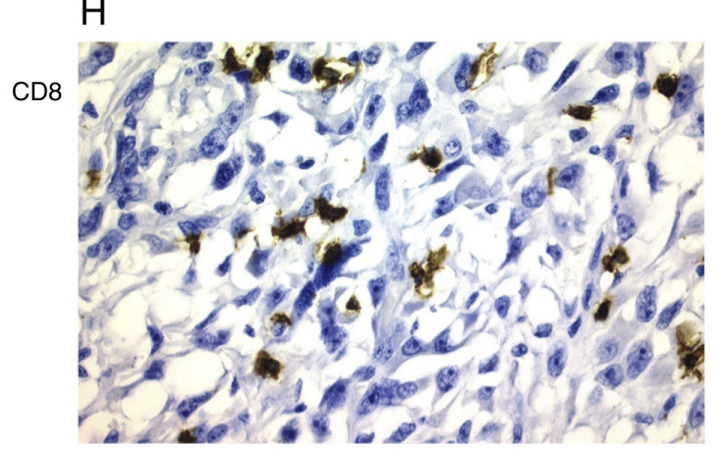

B

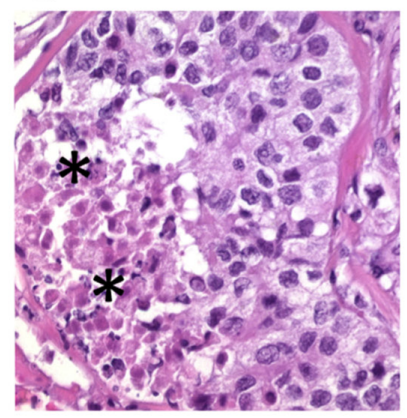

C

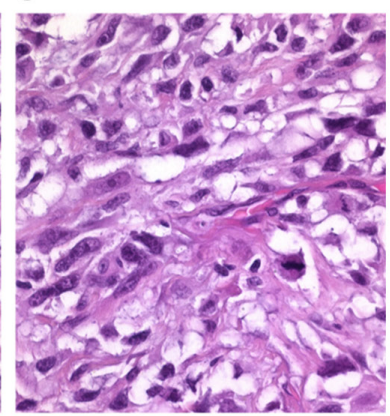

E

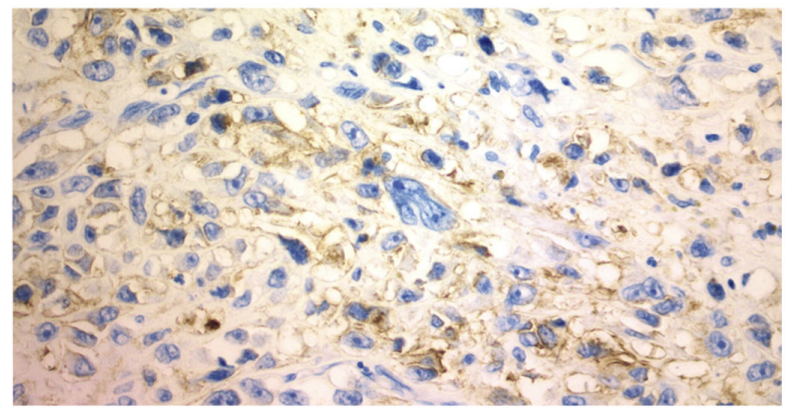

G
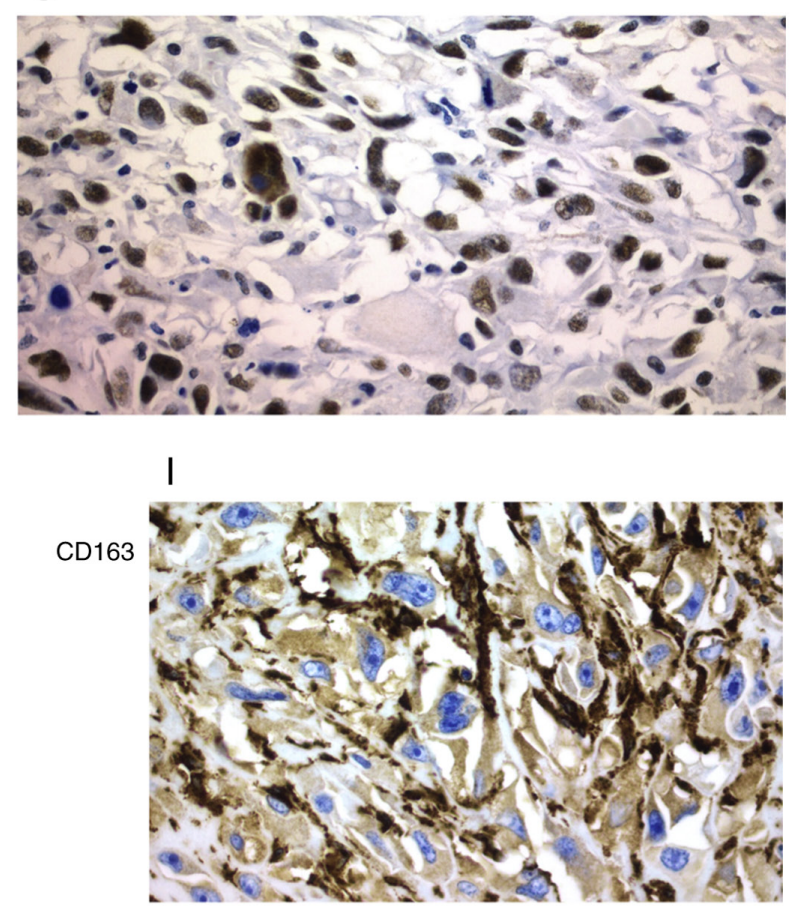

Figure 4. ATC with poorly differentiated areas (case 6). (A) Transition between poorly differentiated areas (arrows) and ATC areas (magnification, x200). Higher magnification shows (B) a poorly differentiated area with a focus of necrosis (asterisks) and (C) another ATC area. (D) Poorly differentiated areas were negative for PD-L1, with (E) positivity for PD-L1 only observed in ATC areas. MLH1 protein expression was detected in both (F) poorly differentiated and $(\mathrm{G})$ ATC areas. (H) A higher density of CD8 ${ }^{+}$lymphocytes was observed in ATC areas than in poorly differentiated areas. (I) CD163 ${ }^{+}$macrophages were only found in the ATC areas of the tumor. Magnification, x400. ATC, anaplastic thyroid carcinoma; H\&E, hematoxylin and eosin; PD-L1, programmed death ligand 1; MLH1, mutL homolog 1.

of neoantigens and changes in the immune system (PD-L1 expression and changes in TME).

In a recent meta-analysis the association of $\mathrm{PD}-\mathrm{L} 1$ and disease-free survival (DFS) remained strong in PTC when compared with dedifferentiated thyroid carcinomas (ATC and PDTC) in which a significant association with PD-L1 was not confirmed (20). In another PDTC series, PD-L1 expression was significantly associated with tumor size and multifocality as well as with a non-significant trend towards older age, metastasis, an increased number of $\mathrm{CD}^{+} \mathrm{T}$ cells and decreased disease-free and overall survival (50). In our series we found a significantly higher expression of PD-L1 in TILs and TAMs 
A

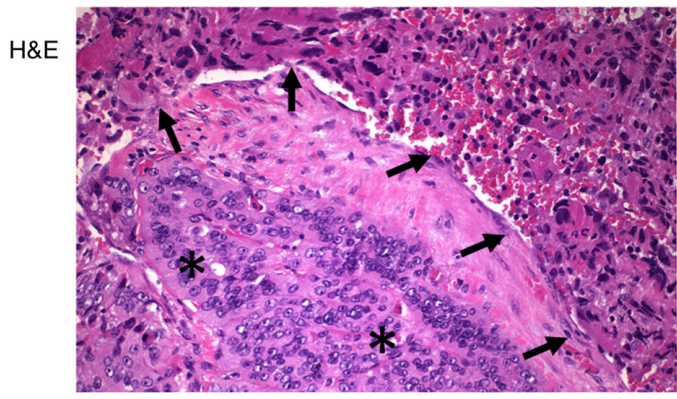

$\mathrm{D}$

PD-L1

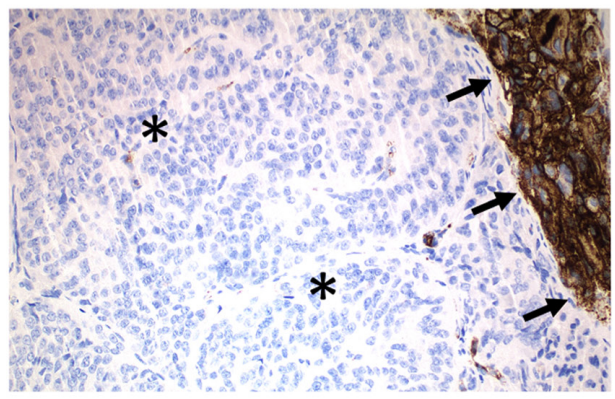

$\mathrm{F}$

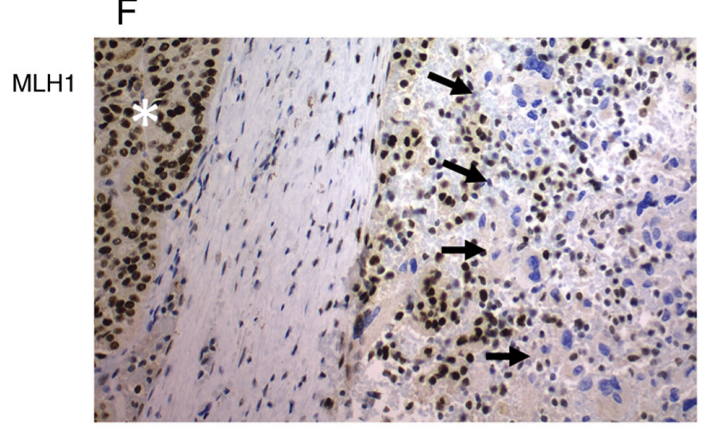

$\mathrm{H}$

CD163

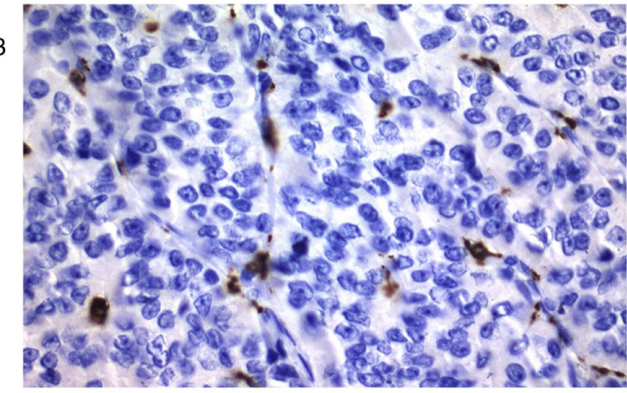

B

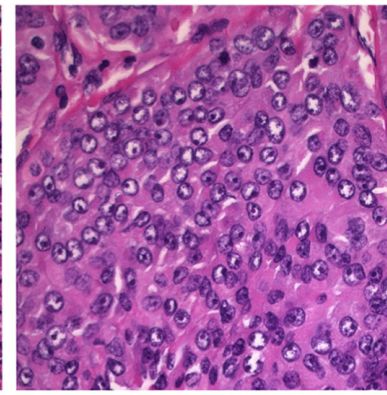

E

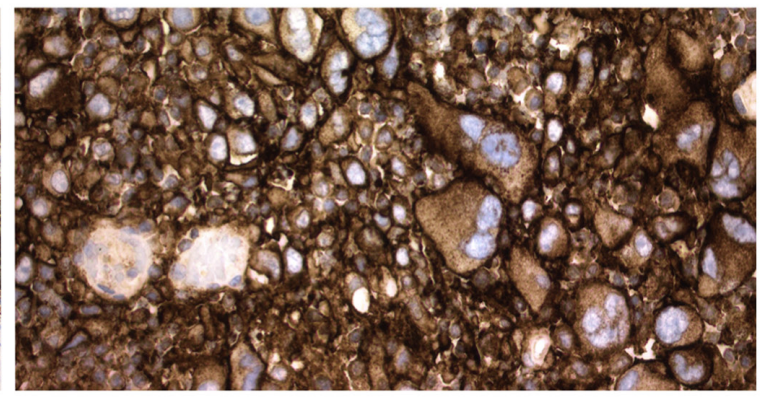

G

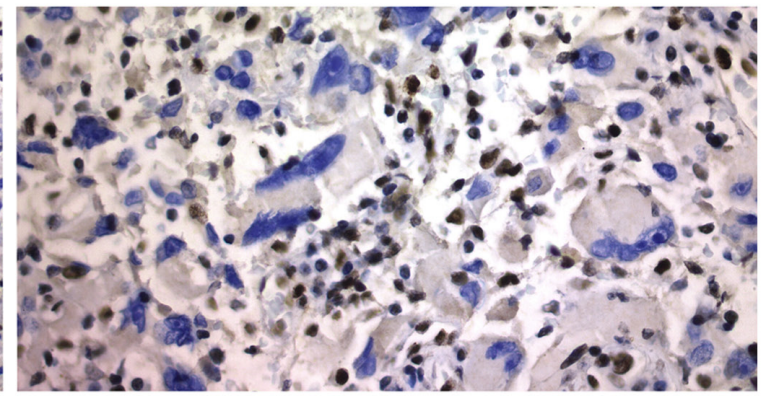

I

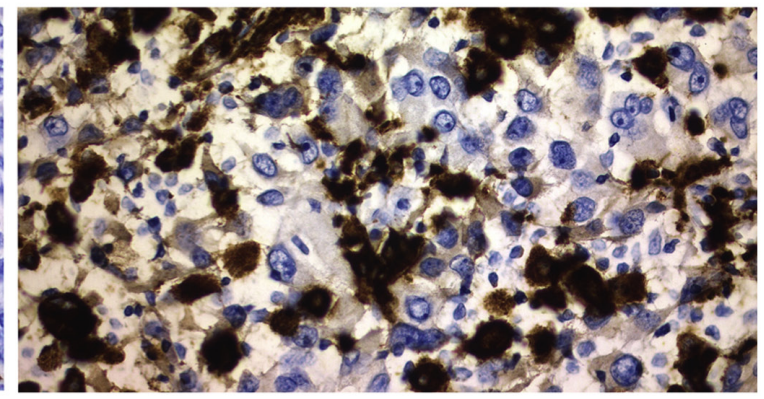

Figure 5. ATC with poorly differentiated areas (case 15). (A) Transition between poorly differentiated areas (asterisks) and ATC areas (arrows) (magnification, $\mathrm{x} 200$ ). Morphological differences between (B) poorly differentiated and (C) ATC areas at a higher magnification (magnification, $\mathrm{x} 400$ ). (D) PD-L1 expression was only detected in the ATC areas (arrows), but not in the poorly differentiated component (asterisks) (magnification, x200). (E) ATC cells showed strong and diffuse positivity for PD-L1 (magnification, $\mathrm{x} 400$ ). MLH1 expression at magnification (F) x200 and (G) x400 was found in the poorly differentiated areas (asterisk), but not in the ATC areas (arrows). CD163 $3^{+}$macrophages were not detected in (H) the poorly differentiated areas, but were heavily detected in (I) the ATC areas (magnification, x400). ATC, anaplastic thyroid carcinoma; H\&E, hematoxylin and eosin; PD-L1, programmed death ligand 1; MLH1, mutL homolog 1 .

in ATC group when compared to the same expression in the PDTC group $(\mathrm{P}=0.0001)$. We also found a trend towards worse survival in ATC with PD-L1 expression in tumor cells, but the figures did not reach statistical significance, probably due to the limited number of cases (Fig. 1B). No trend, however, was evidenced when evaluating PD-L1 expression in TILs and TAMs. A meta-analysis of non-medullary TC comprising
721 positive studies showed an association between PD-L1 expression and disease recurrence (49). PD-L1 up-regulation has recently been associated with poor disease-specific survival in patients with ATC or advanced DTC (43). This association between PD-L1 expression and a poor prognosis has also been confirmed in other tumors from different locations such as head and neck $(80)$, breast $(81)$, kidney $(81,82)$, urothelial 
carcinoma (83), non-small cell lung cancer (84), colorectal cancer $(85)$, and other solid tumors $(81,86)$.

Although this study has several limitations such as its retrospective nature and the limited number of the sample, which could lead to selection biases, there are invaluable data in relation to immunotherapy. In fact, we can conclude that PD-L1 expression and tumor infiltration by $\mathrm{CD}^{+} \mathrm{CD}^{+}$ T lymphocytes, $\mathrm{S} 100^{+}$dendritic cells and $\mathrm{CD} 68^{+} \mathrm{CD} 163^{+}$ macrophages is common in ATC but rare in PDTC. Our findings also suggest that microsatellite instability may also play a role in both TME as well as in the identification of immunotherapy candidates among PDTC patients.

\section{Acknowledgements}

Not applicable.

\section{Funding}

The present study was supported in part by grant no. ISCIII-PI19/01316 from Instituto de Salud Carlos III, State Research Agency and Ministry of Science and Innovation (Spain), with the participation of European FEDER funds.

\section{Availability of data and materials}

All data generated or analyzed during this study are included in this published article.

\section{Authors' contributions}

SCG, IAN, GRC, JGG and JMCT designed the study. SCG, GRC and JGG collected the clinical data. JMCT and GRC are responsible for confirming the authenticity of the data. SAS and MSA performed the staining. IAN and JMCT evaluated the immunohistochemical data. FGS performed the statistical analysis. SCG, IAN and JMCT wrote the manuscript draft. SCG, SAS, MSA, GRC, JGG, FGS, IAN and JMCT contributed to critical revision of the manuscript for important intellectual content. JMCT obtained financial support. All authors have read and approved the final manuscript.

\section{Ethics approval and consent to participate}

The study was approved by the Santiago-Lugo Medical Research Ethics Committee (Santiago de Compostela, Spain; approval no. 2019/275) and written informed consent was obtained.

\section{Patient consent for publication}

Not applicable.

\section{Authors' information}

SCG, ORCID 0000-0002-2678-7230; SAS, ORCID 0000-0003-3576-1953; MSA, ORCID 0000-0003-0098-4161; GRC, ORCID 0000-0002-2015-7369; JGG, ORCID 0000-0002-5372-2467; FGS, ORCID 0000-0002-9681-1662;
IAN, ORCID 0000-0003-1247-2331; and JMCT, ORCID 0000-0002-5516-8914.

\section{Competing interests}

The authors declare that they have no competing interests.

\section{References}

1. Bray F, Ferlay J, Soerjomataram I, Siegel RL, Torre LA and Jemal A: Global cancer statistics 2018: GLOBOCAN estimates of incidence and mortality worldwide for 36 cancers in 185 countries. CA Cancer J Clin 68: 394-424, 2018.

2. Lloyd RV, Osamura RY, Klöppel G and Rosai J (eds.): WHO Classification of Tumours of Endocrine Organs. IARC, Lyon, 2017.

3. Luster M, Aktolun C, Amendoeira I, Barczyński M, Bible KC, Duntas LH, Elisei R, Handkiewicz-Junak D, Hoffmann M, Jarząb B, et al: European Perspective on 2015 American Thyroid Association Management Guidelines for adult patients with thyroid nodules and differentiated thyroid cancer: Proceedings of an Interactive International Symposium. Thyroid 29: 7-26, 2019.

4. Smallridge RC, Ain KB, Asa SL, Bible KC, Brierley JD, Burman KD, Kebebew E, Lee NY, Nikiforov YE, Rosenthal MS, et al: American Thyroid Association guidelines for management of patients with anaplastic thyroid cancer. Thyroid 22: 1104-1139, 2012.

5. Haddad RI, Nasr C, Bischoff L, Busaidy NL, Byrd D, Callender G, Dickson P, Duh QY, Ehya H, Goldner W, et al: NCCN Guidelines Insights: Thyroid Carcinoma, Version 2.2018. J Natl Compr Canc Netw 16: 1429-1440, 2018.

6. De Leo S, Trevisan M and Fugazzola L: Recent advances in the management of anaplastic thyroid cancer. Thyroid Res 13: 17, 2020.

7. Volante M, Collini P, Nikiforov YE, Sakamoto A, Kakudo K, Katoh R, Lloyd RV, LiVolsi VA, Papotti M, Sobrinho-Simoes M, et al: Poorly differentiated thyroid carcinoma: The Turin proposal for the use of uniform diagnostic criteria and an algorithmic diagnostic approach. Am J Surg Pathol 31: 1256-1264, 2007.

8. Xu B and Ghossein R: Poorly differentiated thyroid carcinoma. Semin Diagn Pathol 37: 243-247, 2020.

9. Akaishi J, Kondo T, Sugino K, Ogimi Y, Masaki C, Hames KY, Yabuta T, Tomoda C, Suzuki A, Matsuzu K, et al: Prognostic impact of the Turin criteria in poorly differentiated thyroid carcinoma. World J Surg 43: 2235-2244, 2019.

10. Walczyk A, Kopczyński J, Gąsior-Perczak D, Pałyga I, Kowalik A, Chrapek M, Hejnold M, Góźdź S and Kowalska A: Histopathology and immunohistochemistry as prognostic factors for poorly differentiated thyroid cancer in a series of Polish patients. PLoS One 15: e0229264, 2020.

11. Dettmer M, Schmitt A, Steinert H, Haldemann A, Meili A, Moch H, Komminoth P and Perren A: Poorly differentiated thyroid carcinomas: How much poorly differentiated is needed? Am J Surg Pathol 35: 1866-1872, 2011.

12. Dettmer M, Schmitt A, Steinert H, Moch H, Komminoth P and Perren A: Poorly differentiated oncocytic thyroid carcinoma-diagnostic implications and outcome. Histopathology 60: 1045-1051, 2012.

13. Bai S, Baloch ZW, Samulski TD, Montone KT and LiVolsi VA: Poorly differentiated oncocytic (Hürthle cell) follicular carcinoma: An institutional experience. Endocr Pathol 26: 164-169, 2015.

14. Wang JR, Zafereo ME, Dadu R, Ferrarotto R, Busaidy NL, Lu C, Ahmed S, Gule-Monroe MK, Williams MD, Sturgis EM, et al: Complete Surgical resection following neoadjuvant dabrafenib plus trametinib in $\mathrm{BRAF}^{600 \mathrm{E}}$-mutated anaplastic thyroid carcinoma. Thyroid 29: 1036-1043, 2019.

15. Takahashi S, Tahara M, Ito K, Tori M, Kiyota N, Yoshida K, Sakata Y and Yoshida A: Safety and effectiveness of lenvatinib in 594 patients with unresectable thyroid cancer in an all-case post-marketing observational study in Japan. Adv Ther 37: 3850-3862, 2020.

16. Hanna GJ, Busaidy NL, Chau NG, Wirth LJ, Barletta JA, Calles A, Haddad RI, Kraft S, Cabanillas ME, Rabinowits G, et al: Genomic correlates of response to everolimus in aggressive radioiodine-refractory thyroid cancer: A phase II study. Clin Cancer Res 24: 1546-1553, 2018. 
17. Harris EJ, Hanna GJ, Chau N, Rabinowits G, Haddad R, Margalit DN, Schoenfeld J, Tishler RB, Barletta JA, Nehs M, et al: Everolimus in anaplastic thyroid cancer: A case series. Front Oncol 9: 106, 2019.

18. Ha HT, Lee JS, Urba S, Koenig RJ, Sisson J, Giordano T and Worden FP: A phase II study of imatinib in patients with advanced anaplastic thyroid cancer. Thyroid 20: 975-980, 2010

19. Capdevila J, Wirth LJ, Ernst T, Ponce Aix S, Lin CC, Ramlau R, Butler MO, Delord JP, Gelderblom H, Ascierto PA, et al: PD-1 Blockade in Anaplastic Thyroid Carcinoma. J Clin Oncol 38 2620-2627, 2020.

20. Guan J, Lim KS, Mekhail T and Chang CC: Programmed death ligand-1 (PD-L1) expression in the programmed death receptor-1 (PD-1)/PD-L1 blockade: A key player against various cancers Arch Pathol Lab Med 141: 851-861, 2017.

21. You W, Shang B, Sun J, Liu X, Su L and Jiang S: Mechanistic insight of predictive biomarkers for antitumor PD-1/PD-L1 blockade: A paradigm shift towards immunome evaluation (Review). Oncol Rep 44: 424-437, 2020.

22. Cantara S, Bertelli E, Occhini R, Regoli M, Brilli L, Pacini F, Castagna MG and Toti P: Blockade of the programmed death ligand 1 (PD-L1) as potential therapy for anaplastic thyroid cancer. Endocrine 64: 122-129, 2019.

23. Gunda V, Gigliotti B, Ndishabandi D, Ashry T, McCarthy M, Zhou Z, Amin S, Freeman GJ, Alessandrini A and Parangi S: Combinations of BRAF inhibitor and anti-PD-1/PD-L1 antibody improve survival and tumour immunity in an immunocompeten model of orthotopic murine anaplastic thyroid cancer. $\mathrm{Br}$ J Cancer 119: 1223-1232, 2018.

24. Gunda V, Gigliotti B, Ashry T, Ndishabandi D, McCarthy M, Zhou Z, Amin S, Lee KE, Stork T, Wirth L, et al: Anti-PD-1/PD-L1 therapy augments lenvatinib's efficacy by favorably altering the immune microenvironment of murine anaplastic thyroid cancer Int J Cancer 144: 2266-2278, 2019.

25. Moretti S, Menicali E, Nucci N, Guzzetti M, Morelli S and Puxeddu E: Therapy of endocrine disease Immunotherapy of advanced thyroid cancer: From bench to bedside. Eur J Endocrinol 183: R41-R55, 2020.

26. Mehnert JM, Varga A, Brose MS, Aggarwal RR, Lin CC Prawira A, de Braud F, Tamura K, Doi T, Piha-Paul SA, et al: Safety and antitumor activity of the anti-PD-1 antibody pembrolizumab in patients with advanced, PD-L1-positive papillary or follicular thyroid cancer. BMC Cancer 19: 196, 2019

27. Chintakuntlawar AV, Yin J, Foote RL, Kasperbauer JL, Rivera M Asmus E, Garces NI, Janus JR, Liu M, Ma DJ, et al: A phase 2 study of pembrolizumab combined with chemoradiotherapy as initial treatment for anaplastic thyroid cancer. Thyroid 29: 1615-1622, 2019.

28. Iyer PC, Dadu R, Gule-Monroe M, Busaidy NL, Ferrarotto R, Habra MA, Zafereo M, Williams MD, Gunn GB, Grosu H, et al: Salvage pembrolizumab added to kinase inhibitor therapy for the treatment of anaplastic thyroid carcinoma. J Immunother Cancer 6: 68, 2018.

29. Girolami I, Pantanowitz L, Mete O, Brunelli M, Marletta S, Colato C, Trimboli P, Crescenzi A, Bongiovanni M, Barbareschi $M$ and Eccher A: Programmed Death-Ligand 1 (PD-L1) is a potential biomarker of disease-free survival in papillary thyroid carcinoma: A systematic review and meta-analysis of PD-L1 immunoexpression in follicular epithelial derived thyroid carcinoma. Endocr Pathol 31: 291-300, 2020.

30. Bangaraiahgari R, Panchangam RB, Puthenveetil P, Mayilvaganan S, Bangaraiahgari R, Banala RR, Karunakaran P and $\mathrm{Md} \mathrm{R}$ : Is there adenoma-carcinoma sequence between benign adenoma and papillary cancer of thyroid: A genomic linkage study. Ann Med Surg (Lond) 60: 695-700, 2020.

31. Volante M, Lam AK, Papotti M and Tallini G: Molecular pathology of poorly differentiated and anaplastic thyroid cancer: What do pathologists need to know. Endocr Pathol 32: 63-76, 2021.

32. Soares P, Póvoa AA, Melo M, Vinagre J, Máximo V, Eloy C, Cameselle-Teijeiro JM and Sobrinho-Simões M: Molecular pathology of Non-familial follicular epithelial-derived thyroid cancer in adults: From RAS/BRAF-like tumor designations to molecular risk stratification. Endocr Pathol 32: 44-62, 2021.

33. Jung SH, Kim MS, Jung CK, Park HC, Kim SY, Liu J, Bae JS, Lee SH, Kim TM, Lee SH and Chung YJ: Mutational burdens and evolutionary ages of thyroid follicular adenoma are comparable to those of follicular carcinoma. Oncotarget 7: 69638-69648, 2016 .
34. Chalmers ZR, Connelly CF, Fabrizio D, Gay L, Ali SM, Ennis R, Schrock A, Campbell B, Shlien A, Chmielecki J, et al: Analysis of 100,000 human cancer genomes reveals the landscape of tumor mutational burden. Genome Med 9: 34, 2017.

35. Cancer Genome Atlas Research Network: Integrated genomic characterization of papillary thyroid carcinoma. Cell 159: 676-690, 2014.

36. Landa I, Ibrahimpasic T, Boucai L, Sinha R, Knauf JA, Shah RH, Dogan S, Ricarte-Filho JC, Krishnamoorthy GP, Xu B, et al: Genomic and transcriptomic hallmarks of poorly differentiated and anaplastic thyroid cancers. J Clin Invest 126: 1052-1066, 2016.

37. Kunstman JW, Juhlin CC, Goh G, Brown TC, Stenman A, Healy JM, Rubinstein JC, Choi M, Kiss N, Nelson-Williams $C$, et al: Characterization of the mutational landscape of anaplastic thyroid cancer via whole-exome sequencing. Hum Mol Genet 24: 2318-2329, 2015.

38. Riesco-Eizaguirre G and Santisteban P: Endocrine Tumours: Advances in the molecular pathogenesis of thyroid cancer: Lessons from the cancer genome. Eur J Endocrinol 175 R203-R217, 2016.

39. Capdevila J, Mayor R, Mancuso FM, Iglesias C, Caratù G, Matos I, Zafón C, Hernando J, Petit A, Nuciforo P, et al: Early evolutionary divergence between papillary and anaplastic thyroid cancers. Ann Oncol 29: 1454-1460, 2018.

40. Ragazzi M, Torricelli F, Donati B, Ciarrocchi A, de Biase D, Tallini G, Zanetti E, Bisagni A, Kuhn E, Giordano D, et al: Coexisting well-differentiated and anaplastic thyroid carcinoma in the same primary resection specimen: Immunophenotypic and genetic comparison of the two components in a consecutive series of 13 cases and a review of the literature. Virchows Arch 478: 265-281, 2021.

41. Cameselle-Teijeiro JM, Rodríguez-Pérez I, Celestino R, Eloy C, Piso-Neira M, Abdulkader-Nallib I, Soares P and Sobrinho-Simões M: Hobnail variant of papillary thyroid carcinoma: Clinicopathologic and molecular evidence of progression to undifferentiated carcinoma in 2 cases. Am J Surg Pathol 41: 854-860, 2017

42. Ibrahimpasic T, Ghossein R, Shah JP and Ganly I: Poorly Differentiated carcinoma of the thyroid gland: Current status and future prospects. Thyroid 29: 311-321, 2019.

43. Yoo SK, Song YS, Lee EK, Hwang J, Kim HH, Jung G, Kim YA, Kim SJ, Cho SW, Won JK, et al: Integrative analysis of genomic and transcriptomic characteristics associated with progression of aggressive thyroid cancer. Nat Commun 10: 2764, 2019.

44. Hiltzik D, Carlson DL, Tuttle RM, Chuai S, Ishill N, Shaha A, Shah JP, Singh B and Ghossein RA: Poorly differentiated thyroid carcinomas defined on the basis of mitosis and necrosis: A clinicopathologic study of 58 patients. Cancer 106 : 1286-1295, 2006.

45. Gerber TS, Schad A, Hartmann N, Springer E, Zechner U and Musholt TJ: Targeted next-generation sequencing of cancer genes in poorly differentiated thyroid cancer. Endocr Connect 7: 47-55, 2018.

46. Cunha LL, Marcello MA, Morari EC, Nonogaki S, Conte FF, Gerhard R, Soares FA, Vassallo J and Ward LS: Differentiated thyroid carcinomas may elude the immune system by $\mathrm{B} 7 \mathrm{H} 1$ upregulation. Endocr Relat Cancer 20: 103-110, 2013.

47. Ahn S, Kim TH, Kim SW, Ki CS, Jang HW, Kim JS, Kim JH, Choe JH, Shin JH, Hahn SY, et al: Comprehensive screening for PD-L1 expression in thyroid cancer. Endocr Relat Cancer 24: 97-106, 2017.

48. Chowdhury S, Veyhl J, Jessa F, Polyakova O, Alenzi A, MacMillan C, Ralhan R and Walfish PG: Programmed death-ligand 1 overexpression is a prognostic marker for aggressive papillary thyroid cancer and its variants. Oncotarget 7 : 32318-32328, 2016.

49. Aghajani M, Graham S, McCafferty C, Shaheed CA, Roberts T, DeSouza P, Yang T and Niles N: Clinicopathologic and prognostic significance of programmed cell death ligand 1 expression in patients with non-medullary thyroid cancer: A systematic review and meta-analysis. Thyroid 28: 349-361, 2018.

50. Rosenbaum MW, Gigliotti BJ, Pai SI, Parangi S, Wachtel H, Mino-Kenudson M, Gunda V and Faquin WC: PD-L1 and IDO1 are expressed in poorly differentiated thyroid carcinoma. Endocr Pathol 29: 59-67, 2018.

51. Wu H, Sun Y, Ye H, Yang S, Lee SL and de las Morenas A: Anaplastic thyroid cancer: Outcome and the mutation/expression profiles of potential targets. Pathol Oncol Res 21: 695-701, 2015 . 
52. Zwaenepoel K, Jacobs J, De Meulenaere A, Silence K, Smits E, Siozopoulou V, Hauben E, Rolfo C, Rottey S and Pauwels P: CD70 and PD-L1 in anaplastic thyroid cancer-promising targets for immunotherapy. Histopathology 71: 357-365, 2017.

53. Bastman JJ, Serracino HS, Zhu Y, Koenig MR, Mateescu V, Sams SB, Davies KD, Raeburn CD, McIntyre RC Jr, Haugen BR and French JD: Tumor-Infiltrating T cells and the PD-1 checkpoint pathway in advanced differentiated and anaplastic thyroid cancer. J Clin Endocrinol Metab 101: 2863-2873, 2016.

54. Chintakuntlawar AV, Rumilla KM, Smith CY, Jenkins SM, Foote RL, Kasperbauer JL, Morris JC, Ryder M, Alsidawi S, Hilger C and Bible KC: Expression of PD-1 and PD-L1 in anaplastic thyroid cancer patients treated with multimodal therapy: Results from a retrospective study. J Clin Endocrinol Metab 102: 1943-1950, 2017.

55. Kollipara R, Schneider B, Radovich M, Babu S and Kiel PJ: Exceptional response with immunotherapy in a patient with anaplastic thyroid cancer. Oncologist 22: 1149-1151,2017.

56. Aghajani MJ, Cooper A, McGuire H, Jeffries T, Saab J, Ismail K, de Souza P, Bray V, Fazekas de St Groth B, Niles N and Roberts TL: Pembrolizumab for anaplastic thyroid cancer: A case study. Cancer Immunol Immunother 68: 1921-1934, 2019.

57. Stenman A, Hellgren LS, Jatta K, Hysek M, Zemmler M, Altena R, Nilsson IL, Bränström R, Zedenius J and Juhlin CC: Metastatic anaplastic thyroid carcinoma in complete remission: Morphological, molecular, and clinical work-up of a rare case. Endocr Pathol 31: 77-83, 2020.

58. Snyder A, Makarov V, Merghoub T, Yuan J, Zaretsky JM, Desrichard A, Walsh LA, Postow MA, Wong P, Ho TS, et al: Genetic basis for clinical response to CTLA-4 blockade in melanoma. N Engl J Med 371: 2189-2199, 2014.

59. Le DT, Uram JN, Wang $H$, Bartlett BR, Kemberling $H$ Eyring AD, Skora AD, Luber BS, Azad NS, Laheru D, et al: PD-1 Blockade in Tumors with Mismatch-Repair Deficiency. N Engl J Med 372: 2509-2520, 2015.

60. Mehnert JM, Panda A, Zhong H, Hirshfield K, Damare S, Lane K, Sokol L, Stein MN, Rodriguez-Rodriquez L, Kaufman HL, et al: Immune activation and response to pembrolizumab in POLE-mutant endometrial cancer. J Clin Invest 126: 2334-2340, 2016.

61. Duval A and Hamelin R: Mutations at coding repeat sequences in mismatch repair-deficient human cancers: Toward a new concept of target genes for instability. Cancer Res 62:2447-2454, 2002.

62. Peltomäki P: Role of DNA mismatch repair defects in the pathogenesis of human cancer. J Clin Oncol 21: 1174-1179, 2003

63. Mensenkamp AR, Vogelaar IP, van Zelst-Stams WA, Goossens M, Ouchene H, Hendriks-Cornelissen SJ, Kwint MP, Hoogerbrugge N, Nagtegaal ID and Ligtenberg MJ: Somatic mutations in MLH1 and MSH2 are a frequent cause of mismatch-repair deficiency in Lynch syndrome-like tumors Gastroenterology 146: 643-646 e8, 2014.

64. Briggs S and Tomlinson I: Germline and somatic polymerase $\varepsilon$ and $\delta$ mutations define a new class of hypermutated colorectal and endometrial cancers. J Pathol 230: 148-153, 2013.

65. Church DN, Briggs SE, Palles C, Domingo E, Kearsey SJ, Grimes JM, Gorman M, Martin L, Howarth KM, Hodgson SV, et al: DNA polymerase epsilon and $\delta$ exonuclease domain mutations in endometrial cancer. Hum Mol Genet 22: 2820-2828, 2013.

66. Domingo E, Freeman-Mills L, Rayner E, Glaire M, Briggs S, Vermeulen L, Fessler E, Medema JP, Boot A, Morreau H, et al: Somatic POLE proofreading domain mutation, immune response, and prognosis in colorectal cancer: A retrospective, pooled biomarker study. Lancet Gastroenterol Hepatol 1: 207-216, 2016.

67. Petitjean A, Mathe E, Kato S, Ishioka C, Tavtigian SV, Hainaut $P$ and Olivier M: Impact of mutant p53 functional properties on TP53 mutation patterns and tumor phenotype: Lessons from recent developments in the IARC TP53 database. Hum Mutat 28 622-629, 2007

68. Lawrence MS, Stojanov P, Polak P, Kryukov GV, Cibulskis K, Sivachenko A, Carter SL, Stewart C, Mermel CH, Roberts SA, et al: Mutational heterogeneity in cancer and the search for new cancer-associated genes. Nature 499: 214-218, 2013.

69. Poulos RC, Wong YT, Ryan R, Pang H and Wong JWH: Analysis of 7,815 cancer exomes reveals associations between mutational processes and somatic driver mutations. PLoS Genet 14: e1007779, 2018
70. Ahn J, Jin M, Song E, Ryu YM, Song DE, Kim SY, Kim TY, Kim WB, Shong YK, Jeon MJ and Kim WG: Immune profiling of advanced thyroid cancers using fluorescent multiplex immunohistochemistry. Thyroid 31: 61-67, 2021

71. Ferrari SM, Fallahi P, Galdiero MR, Ruffilli I, Elia G, Ragusa F, Paparo SR, Patrizio A, Mazzi V, Varricchi G, et al: Immune and inflammatory cells in thyroid cancer microenvironment. Int J Mol Sci 20: 4413; 2019.

72. French JD, Weber ZJ, Fretwell DL, Said S, Klopper JP and Haugen BR: Tumor-associated lymphocytes and increased FoxP3+ regulatory $\mathrm{T}$ cell frequency correlate with more aggressive papillary thyroid cancer. J Clin Endocrinol Metab 95: 2325-2333, 2010

73. French JD, Kotnis GR, Said S, Raeburn CD, McIntyre RC Jr, Klopper JP and Haugen BR: Programmed death-1+ T cells and regulatory $\mathrm{T}$ cells are enriched in tumor-involved lymph nodes and associated with aggressive features in papillary thyroid cancer. J Clin Endocrinol Metab 97: E934-E943, 2012.

74. Severson JJ, Serracino HS, Mateescu V, Raeburn CD, McIntyre RC Jr, Sams SB, Haugen BR and French JD: PD-1+Tim-3+ CD8+ T lymphocytes display varied degrees of functional exhaustion in patients with regionally metastatic differentiated thyroid cancer. Cancer Immunol Res 3: 620-630, 2015.

75. Hilly O, Koren R, Raz R, Rath-Wolfson L, Mizrachi A, Hamzany Y, Bachar G and Shpitzer T: The role of s100-positive dendritic cells in the prognosis of papillary thyroid carcinoma. Am J Clin Pathol 139: 87-92, 2013.

76. Caillou B, Talbot M, Weyemi U, Pioche-Durieu C, Al Ghuzlan A, Bidart JM, Chouaib S, Schlumberger $M$ and Dupuy C: Tumor-associated macrophages (TAMs) form an interconnected cellular supportive network in anaplastic thyroid carcinoma. PLoS One 6: e22567, 2011.

77. Fang W, Ye L, Shen L, Cai J, Huang F, Wei Q, Fei X, Chen X, Guan H, Wang W, et al: Tumor-associated macrophages promote the metastatic potential of thyroid papillary cancer by releasing CXCL8. Carcinogenesis 35: 1780-1787, 2014.

78. Zhang M, He Y, Sun X, Li Q, Wang W, Zhao A and Di W: A high M1/M2 ratio of tumor-associated macrophages is associated with extended survival in ovarian cancer patients. J Ovarian Res 7: 19,2014

79. Yuan A, Hsiao YJ, Chen HY, Chen HW, Ho CC, Chen YY, Liu YC, Hong TH, Yu SL, Chen JJ and Yang PC: Opposite effects of M1 and M2 macrophage subtypes on lung cancer progression. Sci Rep 5: 14273, 2015.

80. Li J, Wang P and Xu Y: Prognostic value of programmed cell death ligand 1 expression in patients with head and neck cancer: A systematic review and meta-analysis. PLoS One 12: e0179536, 2017.

81. Wang Q, Liu F and Liu L: Prognostic significance of PD-L1 in solid tumor: An updated meta-analysis. Medicine (Baltimore) 96: e6369, 2017

82. Xu F, Xu L, Wang Q, An G, Feng G and Liu F: Clinicopathological and prognostic value of programmed death ligand-1 (PD-L1) in renal cell carcinoma: A meta-analysis. Int J Clin Exp Med 8: 14595-14603, 2015

83. Powles T, Walker J, Andrew Williams J and Bellmunt J: The evolving role of PD-L1 testing in patients with metastatic urothelial carcinoma. Cancer Treat Rev 82: 101925, 2020.

84. Pan ZK, Ye F, Wu X, An HX and Wu JX: Clinicopathological and prognostic significance of programmed cell death ligand1 (PD-L1) expression in patients with non-small cell lung cancer: A meta-analysis. J Thorac Dis 7: 462-470, 2015.

85. Siraj AK, Parvathareddy SK, Annaiyappanaidu P, Haqawi W, Al-Rasheed M, AlManea HM, AlHussaini HF, Al-Dayel F and Al-Kuraya KS: PD-L1 expression is associated with deficient mismatch repair and poor prognosis in middle eastern colorectal cancers. J Pers Med 11: 73, 2021.

86. Walter D, Herrmann E, Schnitzbauer AA, Zeuzem S, Hansmann ML, Peveling-Oberhag J and Hartmann S: PD-L1 expression in extrahepatic cholangiocarcinoma. Histopathology 71: 383-392, 2017.

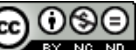

This work is licensed under a Creative Commons Attribution-NonCommercial-NoDerivatives 4.0 International (CC BY-NC-ND 4.0) License. 